\title{
Proteolipid Protein Gene Mutation Induces Altered Ventilatory Response to Hypoxia in the Myelin-Deficient Rat
}

\author{
Martha J. Miller, ${ }^{1}$ Musa A. Haxhiu, ${ }^{1}$ Paraskevi Georgiadis, ${ }^{1}$ Tatyana I. Gudz,${ }^{2}$ Cindy D. Kangas, ${ }^{2}$ and Wendy B. Macklin ${ }^{2}$ \\ ${ }^{1}$ Department of Pediatrics, Case Western Reserve University and Rainbow Babies and Children's Hospital, Cleveland, Ohio 44106, and ${ }^{2}$ Department of \\ Neurosciences, Lerner Research Institute, Cleveland Clinic Foundation, Cleveland, Ohio 44195
}

Pelizaeus Merzbacher disease is an X-linked dysmyelinating disorder of the CNS, resulting from mutations in the proteolipid protein $(P L P)$ gene. An animal model for this disorder, the myelin-deficient (MD) rat, carries a point mutation in the PLP gene and exhibits a phenotype similar to the fatal, connatal disease, including extensive dysmyelination, tremors, ataxia, and death at approximately postnatal day 21 (P21). We postulated that early death might result from disruption of myelinated neural pathways in the caudal brainstem and altered ventilatory response to oxygen deprivation or hypercapnic stimulus. Using barometric plethysmography to measure respiratory function, we found that the MD rat develops lethal hypoxic depression of breathing at P21, but hypercapnic ventilatory response is normal. Histologic examination of the caudal brainstem in the MD rat at this age showed extensive dysmyelination and downregulation of NMDA and to a lesser extent $\mathrm{GABA}_{\mathrm{A}}$ receptors on neurons in the nucleus tractus solitarius, hypoglossal nucleus, and dorsal motor nucleus of the vagus. Unexpectedly, immunoreactive PLP/DM20 was detected in neurons in the caudal brainstem. Not all biosynthetic functions and structural elements were altered in these neurons, because phosphorylated and nonphosphorylated neurofilament and choline acetyltransferase expression were comparable between MD and wild-type rats. These findings suggest that PLP is expressed in neurons in the developing brainstem and that $P L P$ gene mutation can selectively disrupt central processing of afferent neural input from peripheral chemoreceptors, leaving the central chemosensory system for hypercapnia intact.

Key words: proteolipid protein; $\mathrm{MD}$ rat; hypoxic ventilatory response; $\mathrm{NMDA}$ receptor; $\mathrm{GABA}_{\mathrm{A}}$ receptor; dysmyelination

\section{Introduction}

Pelizaeus-Merzbacher disease is an X-linked dysmyelinating disorder characterized by nystagmus, hypotonia, ataxia, spasticity, and mental retardation (for review, see Seitelberger et al., 2002). In the most severe form (connatal), symptoms may develop shortly after birth, with death within the first decade (Boulloche and Aicardi, 1986). In the majority of affected families, mutations (including duplications and deletions) have been found in the proteolipid protein (PLP) gene (Cremers et al., 1987; Raskind et al., 1991; Ellis and Malcom, 1994; Harding et al., 1995, Yamamoto et al., 1998; Garbern et al., 1999; Inoue et al., 1999). PLP is the predominant myelin protein in the CNS, accounting for $\sim 50 \%$ of total myelin protein. Spontaneous mutations of the PLP gene have been described in diverse animals, including the rat [PLP myelin-deficient (MD)], dog, rabbit, and mouse ( jimpy) (Nave, 1994; Knapp, 1996; Garbern et al., 1999; Yool et al., 2000). Almost all rodent PLP mutants, including the MD rat, exhibit a phenotype similar to connatal Pelizaeus-Merzbacher disease, developing tremor and ataxia at 10-12 d, seizures at $16-21 \mathrm{~d}$, and death at 21-28 d. In the MD rat, a point mutation substituting proline for threonine at position 75 occurs in exon 3 of the PLP gene (A to C transversion) (Boison and Stoffel, 1989),

\footnotetext{
Received Aug. 16, 2002; revised Dec. 19, 2002; accepted Dec. 23, 2002.

This work was supported by National Institutes of Health Grant NS-25304 (W.B.M.), the American Heart Association (W.B.M.), the Ross Products Division of Abbott Laboratories (M.J.M., M.A.H.), National Heart, Lung, and Blood Institute Grant HL-56527, and National Institute of Neurological Disorders and Stroke Grant IU54 NS-39407 (M.A.H.). We thank Dr. Yuko Fujita and Dr. Christopher Wilson for helpful advice during this project.

Correspondence should be addressed to Dr. Martha J. Miller, Division of Neonatology, Rainbow Babies and Children's Hospital, Room 3124, 11100 Adelbert Road, Cleveland, OH 44106. E-mail: mjm8@po.cwru.edu. Copyright $\odot 2003$ Society for Neuroscience $\quad 0270-6474 / 03 / 232265-09 \$ 15.00 / 0$
}

which induces dramatic hypomyelination and early cell death of oligodendrocytes in the CNS. How mutation of the PLP gene results in early mortality in humans and affected animals is unknown.

In the rat, control of breathing undergoes significant maturation in the first 2-3 weeks of life, with dramatic changes in the ventilatory response to changes in $\mathrm{CO}_{2}$ and $\mathrm{O}_{2}$ concentration in the blood. Respiratory rate is primarily driven by blood $\mathrm{CO}_{2}$ concentration, and, during postnatal life, sensitivity to this stimulus progressively increases. After birth, lack of $\mathrm{O}_{2}$ elicits a biphasic ventilatory response, consisting of an increase in breathing, followed by a decline. As the animal matures, $\mathrm{O}_{2}$ deprivation elicits a more sustained increase in breathing (for review, see Haddad et al., 1995; Miller et al., 2003). During the first 2 weeks of life, neuronal pathways in the brainstem that regulate breathing also undergo rapid myelination (Jacobson, 1963; Csiza and De Lahunta, 1979). The impact of dysmyelination on postnatal development of the central neural pathways that control breathing has not been investigated.

We speculated that early death characteristic of the MD rat might result from dysmyelination of brainstem pathways necessary for normal respiratory responses to elevated $\mathrm{CO}_{2}$ (hypercapnia) or hypoxia. To test this hypothesis, we compared these responses during development in affected MD pups and wild-type (WT) littermates and found that hypoxia induces a dramatic inhibition of respiration at postnatal day 21 (P21) in the MD rat, although the hypercapnic response was normal. We then investigated histopathology of the caudal brainstem in the MD rat at P21 and found that extensive dysmyelination was accompanied by downregulation of the glutamatergic NMDA $\mathrm{NR}_{1}$ receptor 
subunit, and the $\mathrm{GABA}_{\mathrm{A}}$ receptor. Furthermore, MD PLP/DM20 protein accumulated in neuronal cell bodies as well as in oligodendrocytes in the caudal brainstem of the MD rat. Thus, the MD PLP mutation selectively disrupts autonomic control of respiration during hypoxia, possibly through expression of the mutant PLP/DM20 protein in neurons of the caudal brainstem.

\section{Materials and Methods}

Male MD rat pups were bred at the Lerner Research Institute of the Cleveland Clinic Foundation by mating MD/+ females with normal Wistar males. Affected males were detected by the onset of tremor at day 10-14. All physiology experiments were performed during the light portion of the $12 \mathrm{hr}$ light/dark cycle. All protocols for physiologic research met with previous approval of the Institutional Animal Care and Use Committees of Case Western Reserve University and the Cleveland Clinic Foundation in compliance with the Public Health Services Policy on humane care and use of animals.

Measurement of respiration. At postnatal days 14, 18, and 21-24, pups were placed in a heated, flow-through barometric plethysmograph (BUXCO Electronics, Troy, NY). This apparatus allows non-invasive quantitative measurement of breathing. Affected male pups $(n=18)$ were compared with normal littermate males $(n=19)$. Air flow was maintained at $0.6 \mathrm{l} / \mathrm{min}$. The pups were allowed to adapt to the plethysmograph until they were quiet, eyes closed, with little or no spontaneous movement. Then, after baseline respiration was measured, the respiratory responses to hypercapnia and hypoxia were tested. The normal content of $\mathrm{CO}_{2}$ in ambient air is $<0.7 \%$. To evaluate the response of breathing to an increase in inhaled $\mathrm{CO}_{2}$ above this level (hypercapnia), the inflow to the plethysmograph was switched to the test gas: $10 \% \mathrm{CO}_{2}$, balance $\mathrm{N}_{2}$ and $30 \% \mathrm{O}_{2}$ for $10 \mathrm{~min}$. To evaluate the response of the rat pup to severe hypoxia, the pup was exposed to $8 \%$ inspired oxygen (considered severe hypoxia, as opposed to $21 \%$ oxygen in room air) for $5 \mathrm{~min}$. At the conclusion of the test, the plethysmograph gas flow was returned to air. Respiratory rate (breaths per minute), tidal volume (milliliters per minute of gas expired), and minute ventilation (the volume of air exchanged through the lungs; the product of respiratory rate and tidal volume) was recorded. Minute ventilation was averaged over $20 \mathrm{sec}$ intervals before and during the test gas exposure. For comparison between multiple individuals, minute ventilation was expressed as percentage change from the control period before the test gas, as in previous studies from our laboratory (Miller et al., 2000). Data were expressed as mean \pm SE; statistical analysis was by ANOVA. $p \leq 0.05$ was considered significant.

Immunocytochemistry. MD males and normal littermate male controls or PLP-enhanced green fluorescent protein (EGFP) mice (Mallon et al., 2002) were anesthetized with halothane and then perfused transcardially with $2 \mathrm{ml} / \mathrm{gm}$ room temperature (RT) PBS, containing $2 \mathrm{U} / \mathrm{ml}$ heparin sulfate and then with ice-cold 2, 4, or $4 \%$ paraformaldehyde plus $0.2 \%$ glutaraldehyde buffered with $\mathrm{PBS}$. For detection of the $\mathrm{GABA}_{\mathrm{A}}$ receptor $\beta 2$ subunit and the glutamatergic NMDA $\mathrm{NR}_{1}$ receptor subunit, perfusion with $2 \%$ paraformaldehyde was used, with $24 \mathrm{hr}$ postfixation at $4{ }^{\circ} \mathrm{C}$ in $2 \%$ paraformaldehyde. For detection of choline acetyltransferase (ChAT), rats were perfused with $4 \%$ paraformaldehyde and $0.2 \%$ glutaraldehyde in PBS. Brains were postfixed overnight at $4^{\circ} \mathrm{C}$ in $2 \%$ paraformaldehyde in PBS. For all other immunohistochemistry, $4 \%$ paraformaldehyde perfusion was used, and brains were postfixed for $24 \mathrm{hr}$ at $4^{\circ} \mathrm{C}$ in $4 \%$ paraformaldehyde and then cryoprotected (Watson et al., 1985). For all analyses, coronal sections $(30 \mu \mathrm{m})$ of brain, caudal to the bregma and rostral to the decussation of the pyramids, were cut under ice-cold PBS on a Leica (Nussloch, Germany) VT $1000 \mathrm{~S}$ vibratome and stored at $0^{\circ} \mathrm{C}$ in cryostorage solution. For each immunohistochemical comparison, brains from two to nine individual WT and MD rats were studied.

Free-floating sections were rinsed with PBS at room temperature and then incubated for $60 \mathrm{~min}$ in 3\% normal goat serum (NGS) or milk in PBS. After rinsing in PBS, sections were incubated overnight at $4^{\circ} \mathrm{C}$ in PBS with the following primary antibodies: mouse monoclonal antiNMDA NR 1 , 6021A (1:1000; BD PharMingen, San Diego, CA); mouse monoclonal anti-GABA $\beta 2$ subunit, MAB341 (1:1000; Chemicon, Te- mecula, CA); mouse anti-neuronal nuclei (NeuN), MAB377 (1:1000; Chemicon); PLP/DM20 antibody, clone AA3 (1:1000; gift from Steven Pfeiffer, University of Connecticut Health Science Center, Farmington CT); mouse anti-SMI31 monoclonal antibody (1:10,000; Sternberger Monoclonals, Lutherville, MD); mouse anti-SMI32 monoclonal antibody (1:3000; Sternberger Monoclonals); and goat anti-ChAT AB144p (1:500; Chemicon). Sections were then rinsed three times in PBS and incubated for $60 \mathrm{~min}$ in 3\% NGS or milk with secondary antibody. For immunofluorescence, the incubation with secondary antibody was 45 min at RT, before washing and mounting in Vectashield with $20 \% 4^{\prime}, 6^{\prime}$ diamidino-2-phenylindole (DAPI).

For bright-field microscopy, sections were washed in PBS and then incubated for 30 min in $1 \% \mathrm{H}_{2} \mathrm{O}_{2}$ and $10 \%$ Triton X-100 at room temperature; then sections were incubated with primary antibody. The sections were then washed and incubated with the appropriate biotinylated secondary antibody (Vector Laboratories, Burlingame, CA) in 3\% NGS or milk in PBS for 60 min at RT. After rinsing with PBS three times, sections were incubated for $60 \mathrm{~min}$ in $\mathrm{ABC}$ solution (1:1000; Vectashield), rinsed in PBS, incubated 2 min in DAB, rinsed in PBS, posttreated with $0.08 \%$ osmium tetroxide in water for $20 \mathrm{sec}$, rinsed in PBS, incubated $5 \mathrm{~min}$ in $60 \%$ glycerol, mounted in PBS, air dried, and coverslipped with glycerol. For ChAT, sections from tissue prepared as described above were washed with PBS and incubated 30 min in PBS containing $1 \% \mathrm{H}_{2} \mathrm{O}_{2}$ and $10 \%$ Triton $\mathrm{X}-100$. After washing in PBS, the sections were blocked with PBS containing 5\% milk. Sections were again washed in PBS and then incubated at $4^{\circ} \mathrm{C}$ for $72 \mathrm{hr}$ with the primary antibody. After washing in PBS, the sections were incubated at RT with donkey anti-goat secondary antibody in PBS with 5\% milk (1:1000; Jackson ImmunoResearch, West Grove, PA). After rinsing in PBS, sections were incubated for $60 \mathrm{~min}$ at $\mathrm{RT}$ in $\mathrm{ABC}$ solution (1:1000), washed in PBS, and incubated for $5 \mathrm{~min}$ in $1 \mathrm{~m}$ Tris buffer, $\mathrm{pH}$ 7.6. Sections were then incubated in DAB in $1 \mathrm{~m}$ Tris, with $2 \%$ nickel ammonium sulfate, and $0.4 \% \mathrm{H}_{2} \mathrm{O}_{2}$. Sections were then washed in PBS, incubated for $20 \mathrm{sec}$ in $4 \% \mathrm{OsO}_{4}$, washed in $\mathrm{PBS}$, and incubated for $5 \mathrm{~min}$ in $60 \%$ glycerol before mounting.

For staining with cresyl violet, tissues were first washed in PBS, mounted onto slides, and then dehydrated in an $80^{\circ} \mathrm{C}$ oven before incubation for $3 \mathrm{~min}$ in $0.1 \%$ cresyl violet. Slides were then rinsed in deionized water and dehydrated through a series of alcohols and xylene before mounting in Permount.

Quantification of cells in nuclei of the caudal brainstem. To determine total cell density and neuronal cell number, sections were stained with DAPI or with NeuN antibody. Cells were quantified in the nucleus tractus solitarius (NTS), the dorsal motor nucleus of the vagus (DMV), and the hypoglossal nucleus in five WT and five MD rats at P21. Location of these nuclei was defined as in The Rat Brain in Stereotaxic Coordinates (Paxinos and Watson, 1986). Cell counts were verified by two investigators. Areas counted comprised 4.8, 1.8, and $3.0 \times 10^{6} \mu \mathrm{m}^{3}$, respectively. Numbers of cells were compared in WT and MD ( $n=5$ in each group) by paired $t$ test.

Immunoblot. Tissue lysates were made using lysis buffer: $0.15 \mathrm{M} \mathrm{NaCl}$, $0.05 \mathrm{~m}$ Tris, 0.5 mм EDTA, $1 \%$ Triton X-100, and 0.05\% SDS, pH 7.5, supplemented with a protease inhibitor cocktail $(20 \mu \mathrm{g} / \mathrm{ml}$ leupeptin, $100 \mu \mathrm{g} / \mathrm{ml}$ aprotinin, $2 \mathrm{~mm}$ PMSF, and $5 \mathrm{~mm} N$-ethylmaleimide). After 1 $\mathrm{hr}$ on ice, samples were centrifuged at $15,000 \times g$ for $10 \mathrm{~min}$ to remove insoluble material. Supernatant protein concentrations were determined by the bicinchoninic acid method (Sigma, St. Louis, MO).

Lysates were separated on 8.5\% SDS-PAGE, blotted to the polyvinylidene difluoride membrane, blocked with $5 \%$ nonfat dry milk in TBS-T buffer ( $10 \mathrm{~mm}$ Tris, $150 \mathrm{~mm} \mathrm{NaCl}$, and $0.2 \%$ Tween 20, pH 8.0) overnight at $4^{\circ} \mathrm{C}$, and subsequently probed with appropriate antibody according to Gudz et al. (2002). Immunoreactive bands were visualized using an enhanced chemiluminescence kit (ECL-Plus; Amersham Biosciences, Piscataway, NJ).

\section{Results}

\section{Physiologic responses to hypoxia and hypercapnia}

At P14, P18, and P21-P24, there was no difference in respiratory rate, or tidal volume, and thus no difference in minute ventilation 

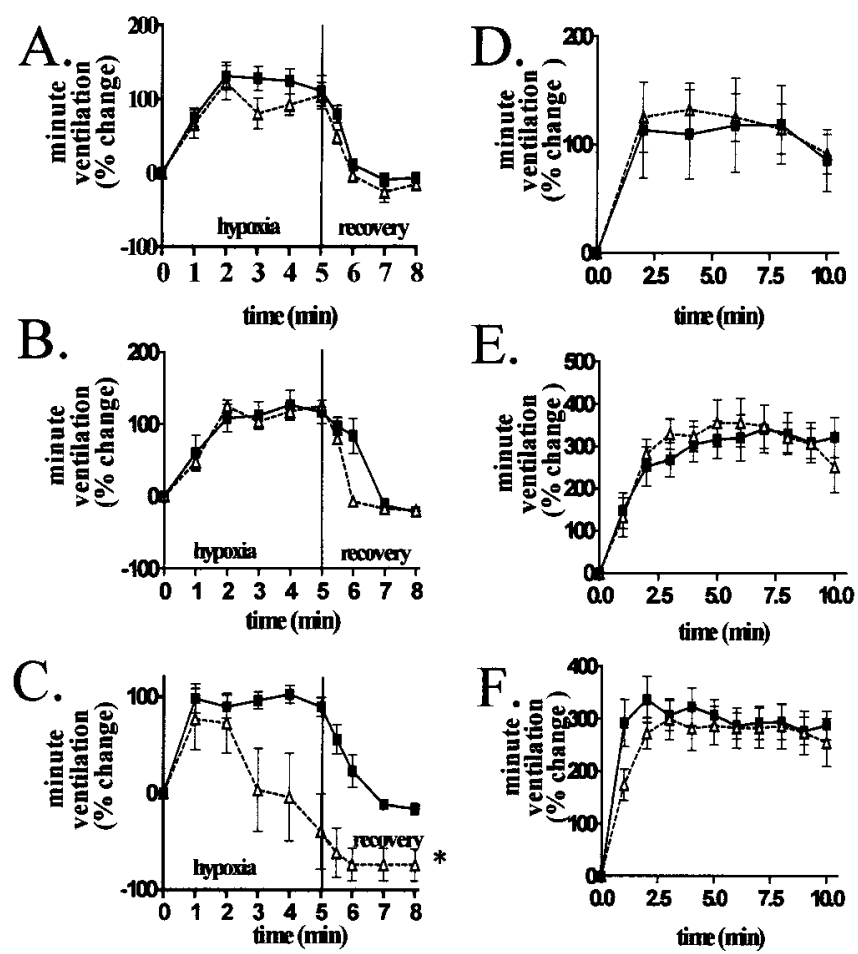

Figure 1. Ventilatory response to inhalation of $8 \% \mathrm{O}_{2}$ or $10 \% \mathrm{CO}_{2}$ in the wild-type $(n=19)$ and $\mathrm{MD}(n=18)$ rat. MD affected males (open triangles) and normal male littermates (filled squares) exhibited similar responses to inhalation of $8 \% \mathrm{O}_{2}$ for $5 \mathrm{~min}$ (P14, A; P18, B). At P21-P24, MD rats exhibited significant depression of ventilation in response to $8 \% \mathrm{O}_{2}$ compared with wild-type males (C) $\left(^{*} p<0.05\right)$. At all ages, the ventilatory response to inhalation of $10 \% \mathrm{CO}_{2}$ for $10 \mathrm{~min}$. was not different in the MD and wild-type rats (P14, D;P18, E; P21-P24,F).

(the product of tidal volume and respiratory rate) between MD and WT littermate males at rest. No prolonged apnea, defined as prolongation of expiratory duration $>2 \mathrm{sec}$, was detected in either group. When the respiratory response to an increase in inhaled carbon dioxide $\left(10 \% \mathrm{CO}_{2}, 30 \% \mathrm{O}_{2}\right.$, and balance $\mathrm{N}_{2}$ for 10 min) was tested at P14, P18, or P21, there was no difference between the responses of the MD males and normal male littermate controls. At P14 and P18, there was also no significant difference in the ventilatory response to hypoxia $\left(8 \% \mathrm{O}_{2}\right.$ and balance $\mathrm{N}_{2}$ for $5 \mathrm{~min}$ ) (Fig. $1 A, B$ ). However, when the ventilatory response to hypoxia was tested at P21-P24, the MD males exhibited a striking depression of breathing after $2 \mathrm{~min}$ of inhalation of hypoxic gas $(p<0.001$; MD vs WT at P21) (Fig. $1 C$ ). This severe hypoxic depression in the MD pups resulted in death of five of seven animals during hypoxic exposure at this age.

The dramatic hypoxic depression of breathing coupled with a normal hypercapnic response in the MD rat at P21-P24 suggested that expression of the abnormal PLP gene in this mutant could have selectively affected the central neural pathways that govern the response of breathing to hypoxia. Therefore, we focused our investigation on the neuronal nuclei within the caudal brainstem that are involved in central processing of sensory input from the peripheral sensors of hypoxia (the carotid bodies). Specifically, we studied the caudal brainstem at the area of the commissural nucleus of the NTS, which is the predominant site for synapse of afferent fibers from the carotid bodies. From this nucleus, adjacent areas, such as the DMV and the hypoglossal nucleus, receive efferent input from the NTS.
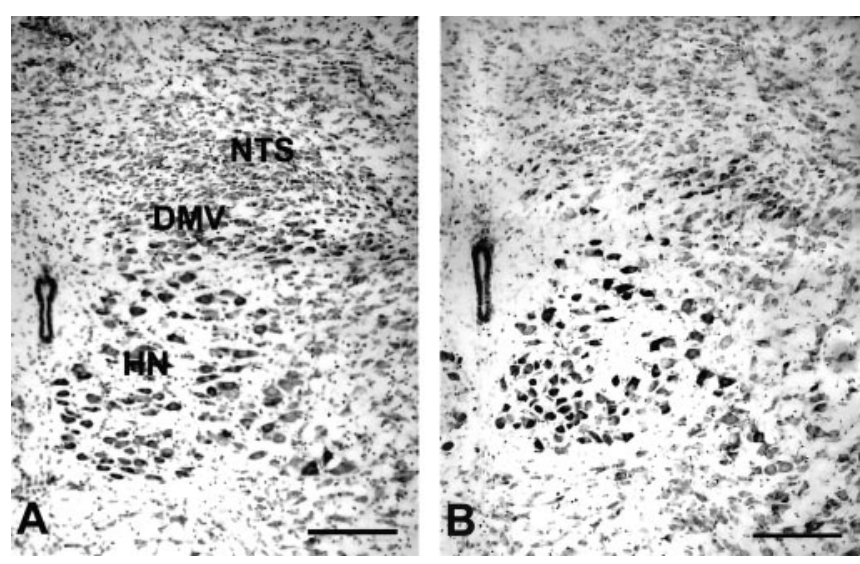

Figure 2. Cells stained with cresyl violet were evenly distributed at the level of the area postrema in the caudal brainstem in P21 wild-type rats $(A)$ and MD rats (B). Scale bar, $100 \mu \mathrm{m}$.

Table 1. Density of total cells and NeuN-immunoreactive cells in the caudal brainstem

\begin{tabular}{llllll}
\hline \multirow{2}{*}{ Nucleus } & \multicolumn{2}{l}{ Total cells $^{a}$} & & \multicolumn{2}{l}{ NeuN-immunoreactive cells } \\
\cline { 2 - 3 } \cline { 5 - 6 } & WT & MD & & WT & MD \\
\hline NTS & $75.6 \pm 8.4$ & $73.1 \pm 12.2$ & & $50.4 \pm 8.4$ & $40.8 \pm 12.2$ \\
DMV & $63.8 \pm 10.6$ & $67.7 \pm 6.6$ & & $24.1 \pm 10$ & $21.3 \pm 5.6$ \\
HYP & $94.0 \pm 16.0$ & $96.0 \pm 26$ & & $25.2 \pm 3.0$ & $21.4 \pm 3.9^{b}$ \\
\hline
\end{tabular}

${ }^{a}$ Cells per $10^{+6} \mu \mathrm{m}^{3}$, mean \pm SD.

${ }^{b}$ Maximum significance of differences between WT and MD reached $p<0.1$.

HYP, Hypoglossal nucleus.

Cell density within the caudal brainstem in the MD rat

Initial analysis of the areas of interest in the medulla by cresyl violet stain indicated no dramatic change in the tissue at P21 (Fig. 2 ), although a reduction in intensity was noted. To determine whether maturation of the brainstem in the MD rat was accompanied by selective cell loss, the total cell density of specific nuclei at the level of the area postrema (NTS, DMV, and the hypoglossal nucleus) was quantified by DAPI stain. However, no difference in total cell density was observed when comparing these areas in the MD and WT rat (Table 1). To determine the number of neurons in each area, we used the neuron-specific antibody NeuN (Fig. 3), which stains neuronal cell bodies and nuclei (Mullen et al., 1992). Although there were apparent decreases in NeuN-positive neurons in the NTS, DMV, and hypoglossal nuclei, these differences were not statistically significant.

\section{Neurofilament distribution and phosphorylation in neurons} in the medulla

To assess the general neuronal-axonal organization of the caudal medulla in the MD rat, we compared neurofilament expression in MD and WT rats. A similar pattern of staining for nonphosphorylated (Fig. 4) or phosphorylated (data not shown) neurofilament expression in the caudal brainstem was found in MD and WT rats. Thus, the MD mutation does not appear to alter distribution of either phosphorylated or nonphosphorylated neurofilaments at this age.

\section{Myelination and expression of PLP in neurons in the} caudal medulla

Dysmyelination of the CNS and decreased synthesis of PLP/ DM20, myelin basic protein (MBP), and myelin-associated glycoprotein have been described previously in the CNS in the MD rat (Dentinger et al., 1982, Kumar et al., 1990), but no data are 

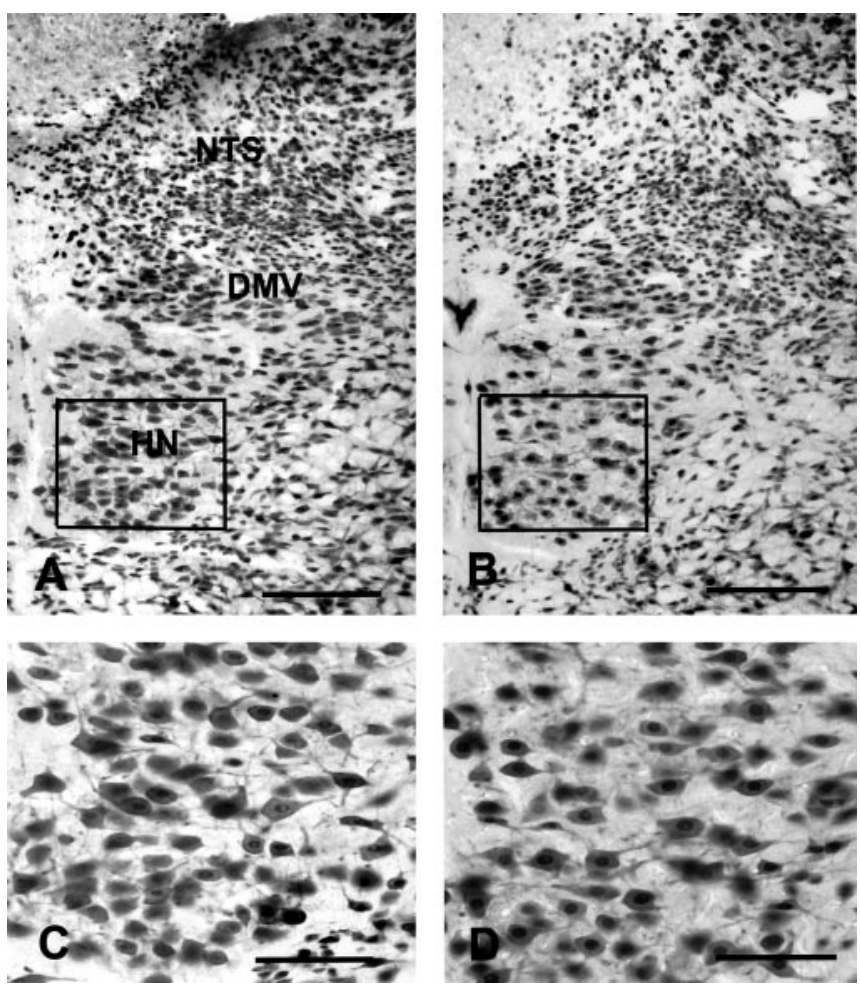

Figure 3. NeuN expression in the MD and WT rat at P21. Neurons were stained throughout the caudal brainstem at the level of the area postrema in the wild-type rat $(A)$ and $M D$ rat $(B)$. There appeared to be reduced staining for NeuN in the nucleus tractus solitarius and the hypoglossal nucleus $(B, D)$, which was not significant when quantified (Table 1). Boxed areas in $A$ and $B$ are enlarged in C and $D$. Scale bars: $A, B, 100 \mu \mathrm{m} ; C, D, 50 \mu \mathrm{m}$.

available on the caudal brainstem. When PLP immunoreactivity was compared in MD and WT littermates, as expected, there was a striking decrease in immunoreactive fibers in the caudal brainstem at the level of the area postrema (Fig. 5). More interestingly, in the MD pup, PLP/DM20 protein was detected in apparent neurons in the hypoglossal nucleus and ventrolateral to that area (Fig. 5B). Thus, it appeared that the PLP gene is transcribed and translated in specific neurons in the respiratory neuraxis of the caudal brainstem in the MD pup.

To confirm that PLP/DM20 protein was present in neurons in the caudal brainstem in the MD rat at $\mathrm{P} 21$, sections from four $\mathrm{MD}$ rats were double labeled for NeuN and PLP/DM20 (Fig. 5). NeuN-positive neurons also expressing PLP/DM20 protein were detected in the hypoglossal motor nucleus and in scattered neurons ventrolateral to this area (Fig. 5D), but no double-labeled neurons were detected in normal WT males (Fig. 5C). Thus, in the MD rat, a neuronal population in the caudal brainstem expresses PLP/DM20 protein, and the mutated protein accumulates in neuronal cell bodies as it does in MD oligodendrocyte cell bodies (Gow et al., 1998). It was striking that, within the caudal brainstem, a subset of neurons expressed the PLP gene, while intermingled in the same region were neurons that appeared to have no PLP in the cell body. The double-labeled neurons were quantified, and neurons accumulating PLP/DM20 in their somas accounted for $55 \%$ (range of $37-69 \%$, in four animals) of neurons in the hypoglossal motor nucleus. This suggests the existence of unique neuronal populations in this area, some of which express the PLP gene and are affected by this mutation and others that do not express the PLP gene and are unaffected by the mutation.
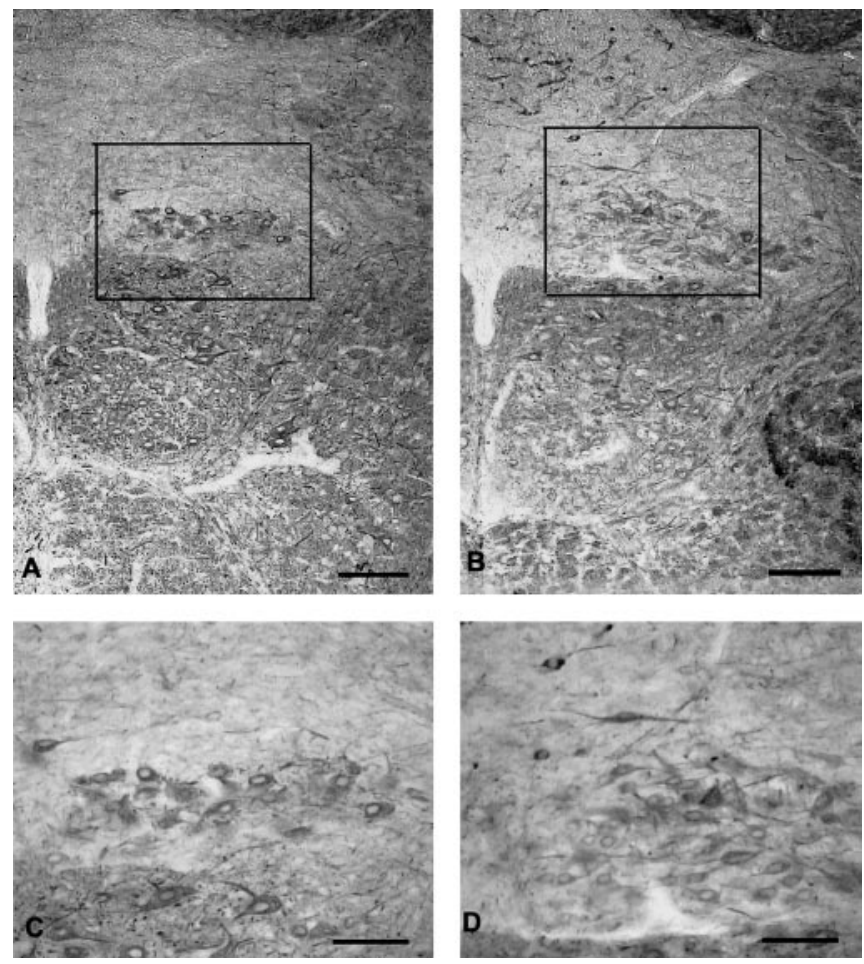

Figure 4. Immunoreactivity for nonphosphorylated neurofilament in the caudal brainstem was distributed similarly in wild-type $(A)$ and $M D(B)$ rats at P21. Boxed areas in $A$ and $B$ are enlarged in $C$ and $D$. Scale bars: $A, B, 100 \mu \mathrm{m} ; C, D, 50 \mu \mathrm{m}$.

To determine whether the PLP gene can be expressed in the caudal brainstem during normal rodent development, we analyzed this area of the brain in the transgenic PLP-EGFP mouse developed in this laboratory (Mallon et al., 2002). This transgenic mouse expresses EGFP under the control of the PLP promoter. Neurons weakly expressing the PLP promoter were identified in the NTS, hypoglossal nucleus, and ventrolateral to this area in the P12 PLP-EGFP mouse by immunoreactivity with NeuN, whereas nontransgenic mice had no green fluorescent signal in neurons (Fig. 6). This observation lends support to our premise that the PLP gene is transcribed and translated in neurons within the caudal medulla during early postnatal development of the rodent and that there is a defect in its processing in neurons in the MD rat.

\section{Glutamatergic NMDA receptor expression in the caudal medulla}

The ventilatory response to hypoxia requires integrity of afferent sensory input from the carotid bodies to the NTS (Cottle, 1964; Panneton and Loewy, 1980; Ciriello et al., 1981; Finley and Katz, 1992; Jordan, 1994). At this nucleus, glutamatergic NMDA receptors on postsynaptic neurons are critical for hypoxia-induced c-fos expression (Haxhiu et al., 1995) and for the increase in ventilation after exposure to hypoxia (Ang et al., 1992; Ogawa et al., 1995; Lin et al., 1996; Ohtake et al., 1998, 2000). We selected the NMDA receptor subunit $R_{1}$ for analysis because this subunit may be required for function of the NMDA receptor (Nakanishi, 1992). When we compared the expression of the NMDA NR subunit in the caudal brainstem at the level of the area postrema, we observed a striking decrease in $\mathrm{NMDA} \mathrm{NR}_{1}$ in the $\mathrm{P} 21 \mathrm{MD}$ rat, relative to littermate controls. Loss of this receptor subunit was particularly evident in the NTS, DMV, and hypoglossal nuclei (Fig. 7). The downregulation of NMDA $\mathrm{NR}_{1}$ receptor subunits appeared limited to the brainstem, because expression of NMDA 

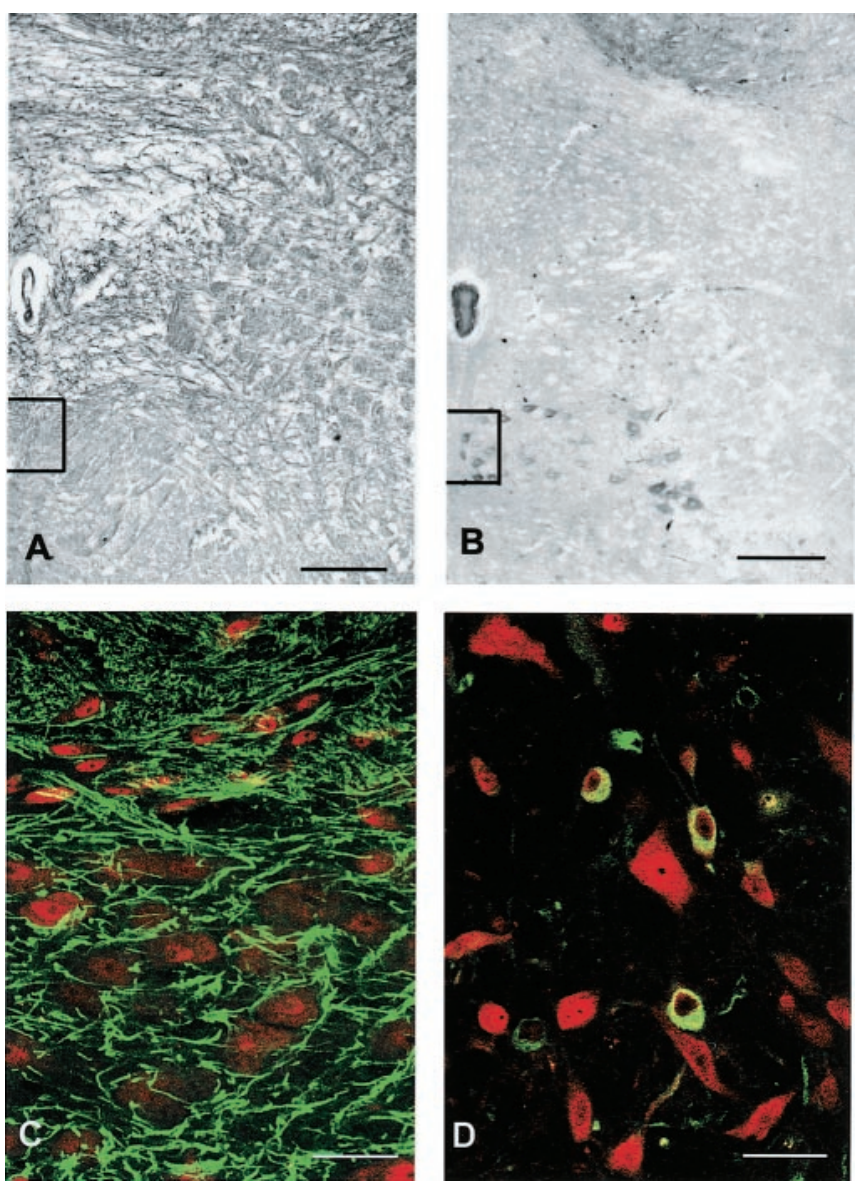

Figure 5. Expression of PLP in the wild-type and MD rat at P21. In the caudal brainstem, immunostaining for PLP was greatly diminished in the MD rat ( $B$ ) compared with the wild type (A). Furthermore, neurons immunoreactive for PLP were present in the hypoglossal nucleus $(B)$. When sections from the wild-type rat were double labeled for NeuN (red) and PLP/DM20 ( $g r e e n)$, no cells immunoreactive for both were observed $(C)$. However, in the MD rat, cells were found that were double labeled for NeuN and PLP/DM20 (yellow) (D). Boxed areas in $A$ and $B$ represent comparable areas with the sites imaged in C and D. Scale bars: $A, B, 100 \mu \mathrm{m}$; $C, D, 33 \mu \mathrm{m}$.

$\mathrm{NR}_{1}$ in the forebrain was normal in the P21 MD rat (data not shown).

\section{Immunoreactive $\mathrm{GABA}_{\mathrm{A}}$ receptors in the caudal medulla}

Activation of $\mathrm{GABA}_{\mathrm{A}}$ receptors in the caudal brainstem also plays a role in the net balance of ventilatory response to hypoxia. This class of receptors in the caudal ventrolateral medulla is tonically active (Miyawaki et al., 2002; Zuperku and McCrimmon, 2002), and activity increases in response to hypoxia-induced GABA release, thereby contributing to depression of ventilation by prolonged or recurrent hypoxia (Melton et al., 1990; Miller et al., 2000; Tabata et al., 2001). On the basis of our physiologic findings, we postulated that profound hypoxic inhibition in the MD rat could reflect a relative imbalance of stimulatory (glutamatergic) and inhibitory (GABAergic) influences on respiratory drive. We therefore analyzed expression of the $\mathrm{GABA}_{\mathrm{A}}$ receptor $(\beta 2$ subunit) in the caudal brainstem of MD and WT rats at P21. In the $\mathrm{MD}$ pup, there was a decrease in immunoreactivity for $\mathrm{GABA}_{\mathrm{A}}$ receptors in the NTS, hypoglossal nucleus, and DMV, as well as the raphe pallidus (Fig. 8). Strong immunostaining was still observed in the area postrema. The focal decrease in $\mathrm{GABA}_{\mathrm{A}}$ receptor immunoreactivity was restricted to the dorsal aspect of
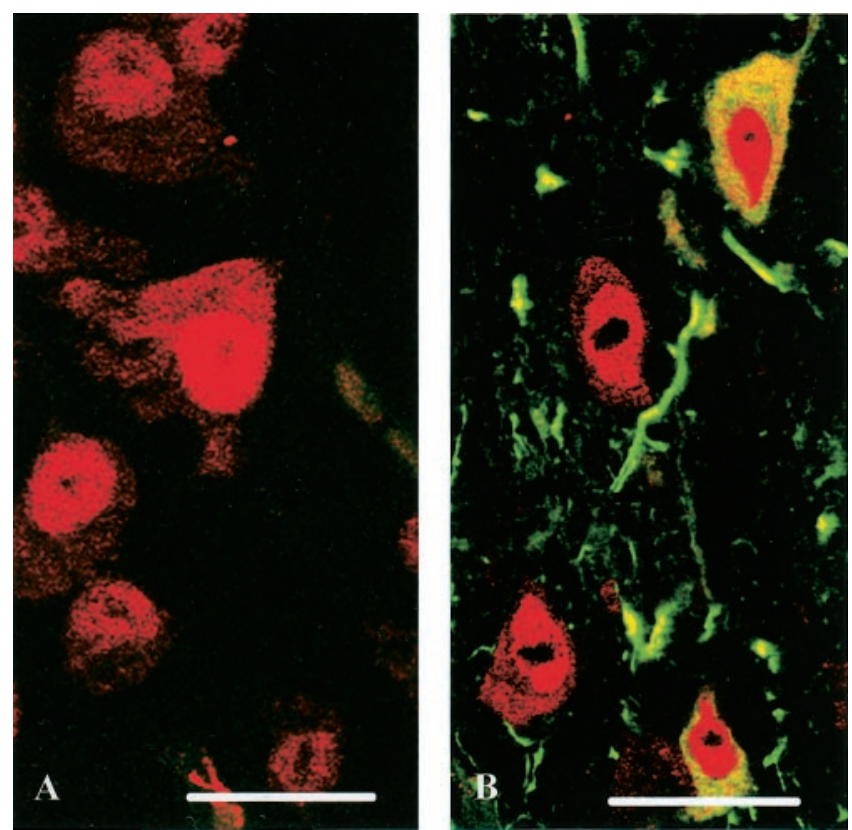

Figure 6. In transgenic mice (P12) expressing the PLP promoter driving expression of EGFP $(B)$, neurons (yellow) were found in the nucleus tractus solitarius that were immunoreactive for NeuN (red) and also expressed EGFP-PLP (green). Nontransgenic mice expressed no autofluorescence in neurons in the NTS $(A)$. Scale bars: $A, B, 33 \mu \mathrm{m}$.

the medulla oblongata and raphe nuclei, because immunostaining of this receptor was normal in the forebrain (data not shown) and was not correlated with a decrease in total $\mathrm{GABA}_{\mathrm{A}}$ receptor $\beta 2$ or $\gamma$ subunit proteins in brainstem (see below).

\section{Expression of choline acetyltransferase in the medulla of the MD rat}

Acetylcholine is the primary neurotransmitter for the motor neurons of the hypoglossal nucleus and the DMV, and cholinergic neurotransmission has been implicated in the ventilatory response to hypercapnia (Loeschcke, 1982). Given the normal response of the MD rat to hypercapnia, we postulated that expression of the biosynthetic enzyme for acetylcholine, ChAT, would be normal in the caudal medulla. As predicted, immunostaining for this enzyme in motor neurons of the caudal medulla in the $\mathrm{MD}$ rat at $\mathrm{P} 21$ was comparable with that in the WT rat (Fig. $9 A, B)$. Thus, these data are consistent with the physiologic finding of intact hypercapnic response in the MD mutation.

\section{Expression of specific proteins in the medulla of MD rats and WT males}

To determine whether the decrease in immunoreactivity for NMDA $\mathrm{NR}_{1}$ and $\mathrm{GABA}_{\mathrm{A}}$ receptors was correlated with a quantitative loss of receptor protein, we performed immunoblot analyses for NMDA NR 1 , the $\mathrm{GABA}_{\mathrm{A}} \beta 2$ and $\gamma$ subunit proteins, as well as PLP/DM20 and MBP in brainstem samples from P21 MD and WT rats (Fig. 10). We found that $\mathrm{NMDA} \mathrm{NR}_{1}$ receptor subunit protein was significantly diminished, as was PLP/DM20 and $\mathrm{MBP}$. However, $\mathrm{GABA}_{\mathrm{A}} \beta 2$ and $\gamma$ receptor subunits were not reduced, relative to wild type. These findings suggest that $\mathrm{GABA}_{\mathrm{A}}$ and NMDA receptors are differentially regulated in the medulla of the MD rat and that, although there are some cells that downregulate $\mathrm{GABA}_{\mathrm{A}}$ receptors in the medulla, $\mathrm{GABA}_{\mathrm{A}}$ neurotransmission is likely to be relatively intact in this tissue. 

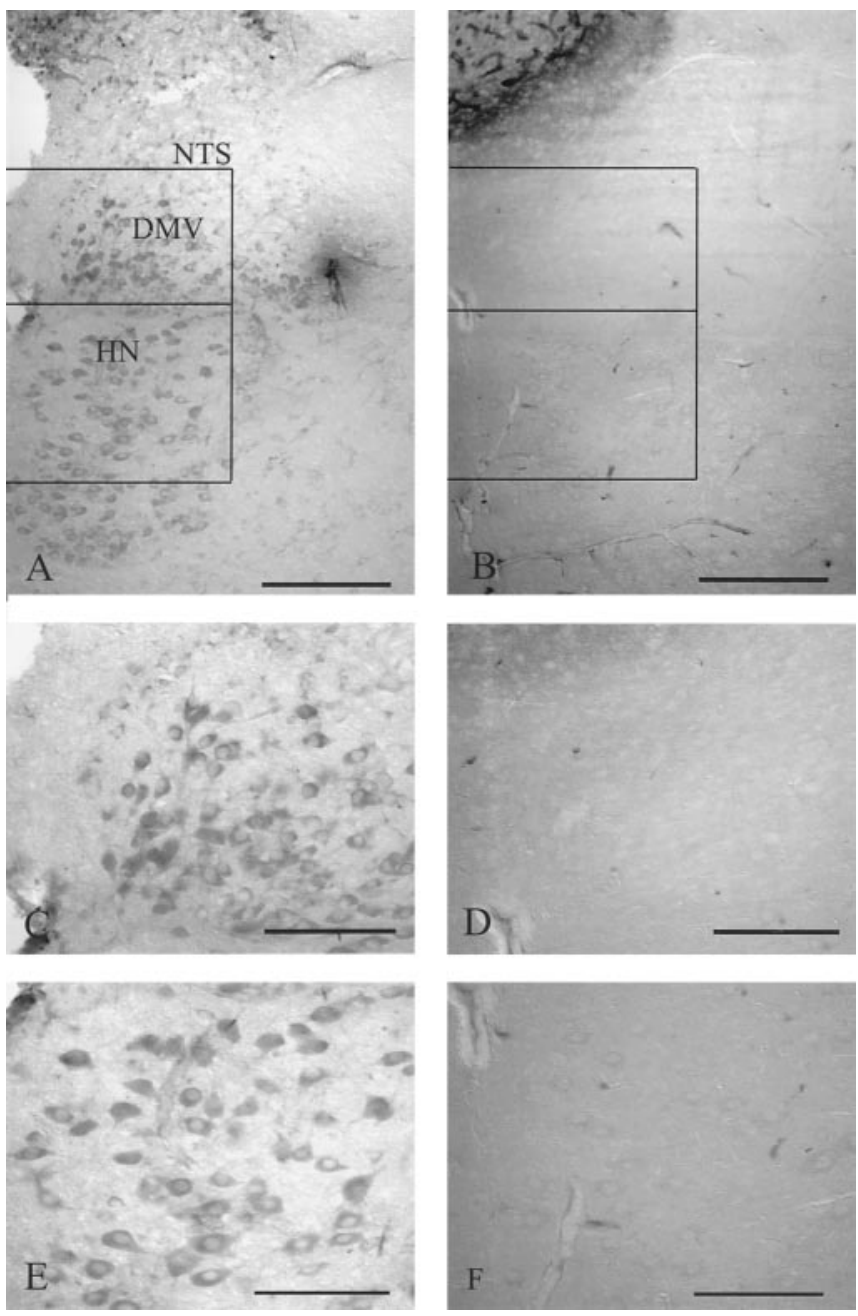

Figure 7. NMDA NR ${ }_{1}$-immunoreactive neurons in the $\mathrm{WT}$ and $\mathrm{MD}$ rat at $\mathrm{P} 21$. In the caudal medulla, at the level of the area postrema, NMDA NR ${ }_{1}$-reactive neurons were observed in the nucleus tractus solitarius, hypoglossal nucleus, and dorsal motor nucleus of the vagus $(A)$. In contrast, in the MD rat, neurons immunoreactive for NMDA NR ${ }_{1}$ were strikingly diminished in these areas ( $B)$. Boxed areas in $A$ and $B$ are enlarged in C $-F$ : top box, $C, D ;$ bottom box, E, F. Scale bars: $A, B, 100 \mu \mathrm{m} ; C-F, 50 \mu \mathrm{m}$.

\section{Discussion}

This study has shown for the first time that the signaling pathway for the hypoxic ventilatory response is altered in the MD rat, at the age of premature death in this mutant. In contrast, hypercapnic ventilatory response is normal, indicating that the MD mutation selectively alters signal transduction pathways in the brainstem involved in response to oxygen deprivation. Furthermore, the fact that respiratory rhythm generation is preserved in the $\mathrm{MD}$ rat, even at $\mathrm{P} 21$, indicates that excitatory input to the rhythm generator from central chemosensory neurons in the ventral medulla is not affected by the MD PLP mutation, nor is descending outflow to spinal cord motoneurons regulating the activity of chest wall pumping muscles.

It is quite striking that the MD mutation does not affect the ventilatory response to hypercapnia. Hypercapnia activates a subset of neurons along the neuraxis that have diverse functions. It has been shown that cholinergic mechanisms in the ventrolateral medulla play an important role in mediation of ventilatory response to changes in $\mathrm{CO}_{2} / \mathrm{H}^{+}$concentration in the extracellular fluid (Loeschcke, 1982). Because ChAT expression in the me-
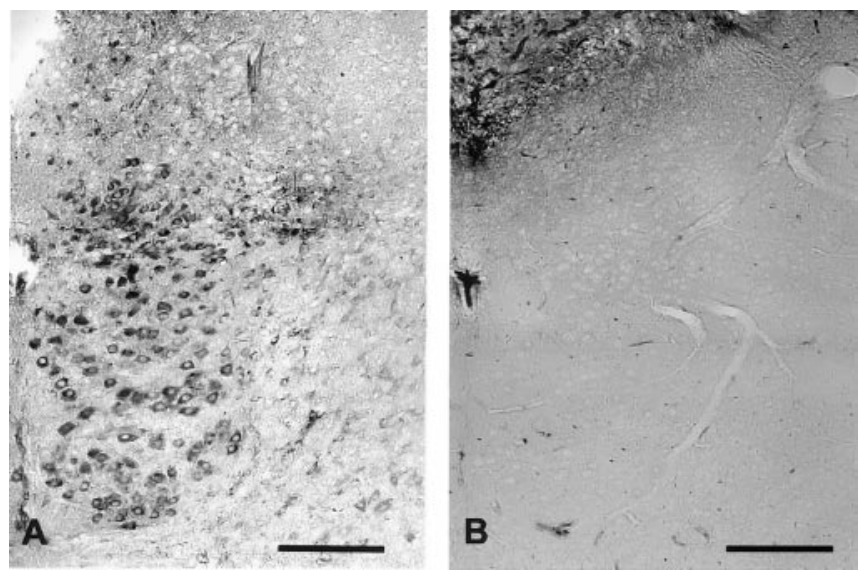

Figure 8. $\quad G_{A B A_{A}} \beta 2$ subunit immunoreactivity in the $W T$ and $M D$ rat at $P 21$. In the caudal brainstem, at the level of the area postrema, $\mathrm{GABA}_{A} \beta 2$ subunit-immunoreactive neurons were present in the nucleus tractus solitarius, dorsal motor nucleus of the vagus, and hypoglossal nucleus $(A)$. Immunoreactivity for this receptor was diminished in the MD rat at P21 (B). Scale bars: $A, B, 100 \mu \mathrm{m}$.
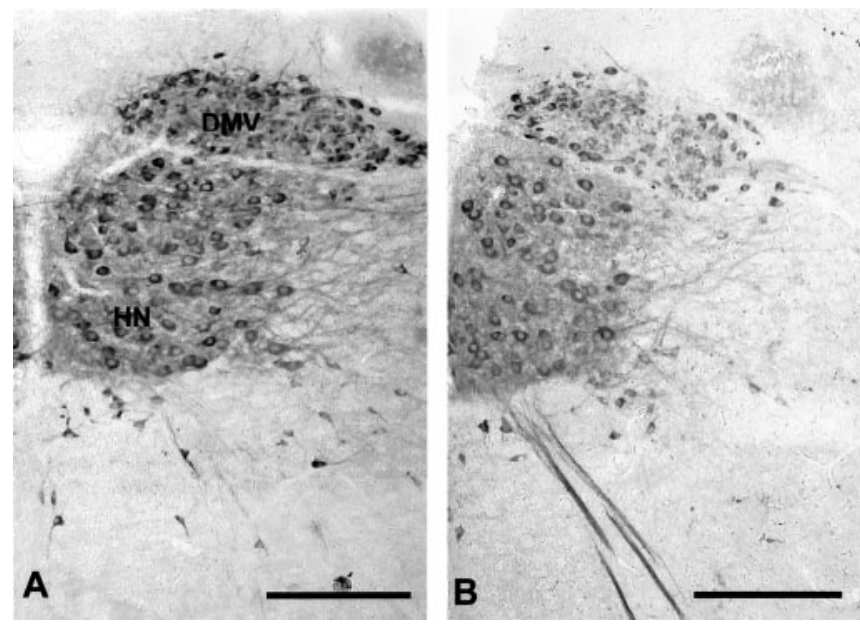

Figure 9. Immunoreactivity for ChAT was similar in the WT $(A)$ and $\mathrm{MD}(B)$ rat in the DMV and hypoglossal nuclei. Scale bars: $A, B, 100 \mu \mathrm{m}$.

dulla oblongata of MD rats is comparable with that observed in WT animals (Fig. 9), unaltered cholinergic mechanisms may explain the preservation of a normal ventilatory response to $\mathrm{CO}_{2}$ in the MD rat.

The ventilatory response to hypoxia in a normal unanesthetized $\mathrm{P} 21$ rat consists of an initial increase in minute ventilation within the first 1-2 min, followed by a sustained increase above baseline, until the hypoxic stimulus is withdrawn (Fig. 1C, WT). The initial phase of the hypoxic response depends on neural inputs from the carotid bodies mainly through the petrosal and jugular ganglia to the caudal NTS. This excitatory input has been shown to require release of glutamate and activation of NMDA receptors on second-order neurons in the NTS (for review, see Gozal and Gaultier, 2001). These neurons project to diverse areas, including the inspiratory rhythm-generating network in the ventrolateral medulla (Loewy and Burton, 1978; Smith et al., 1989). NMDA receptors are critical for the normal ventilatory response to hypoxia in the adult rat (Ohtake et al., 1998, 2000), and deletion of this glutamatergic receptor is lethal in the immediate postnatal period in mice (Funk et al., 1997). 


\section{Brainstem}
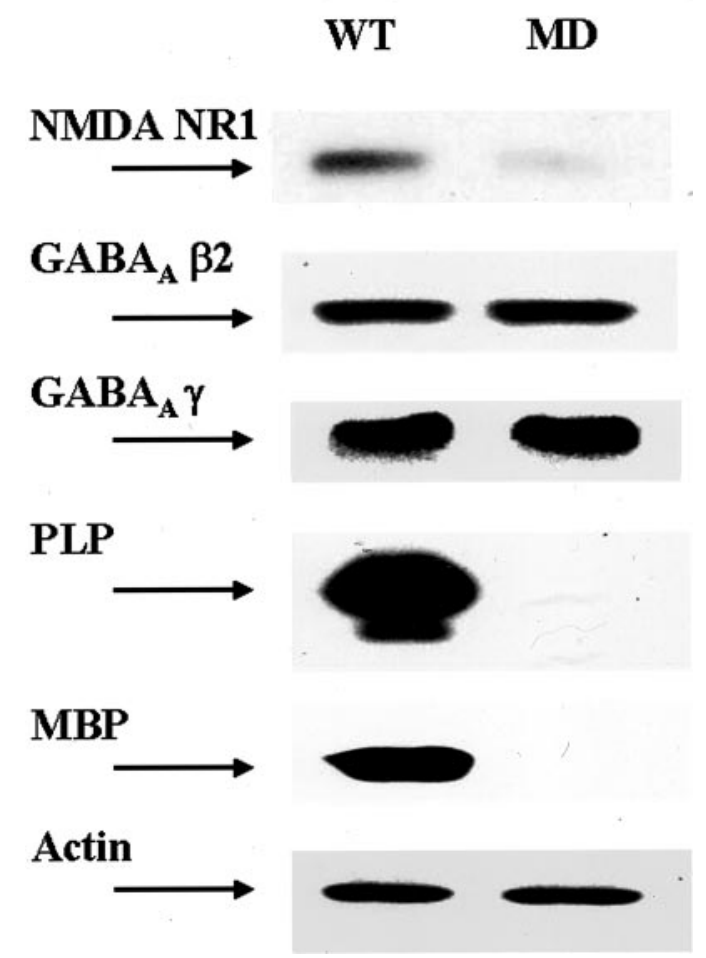

Figure 10. Expression of PLP/DM20, MBP, NMDA NR ${ }_{1}$, and $\mathrm{GABA}_{A} \beta 2$ and $\gamma$ subunits assayed by immunoblot in tissue from the brainstem in the wild-type and MD rat at P21. Actin is present as a loading control. In the MD rat, there was downregulation of NMDA $\mathrm{NR}_{1}, \mathrm{PLP} / \mathrm{DM} 20$, and MBP.

In MD rats, early increase in minute ventilation in response to hypoxia occurs, but it is followed by profound ventilatory depression in the late phase of the hypoxic response. Thus, the initial phase of the hypoxic response is intact in the MD rat, despite the reduction in NMDA receptors in the NTS subnuclei receiving inputs from peripheral chemoreceptors. Conceivably, sufficient NMDA receptors remain for activation of respiratory output to occur, or alternate pathways for generation of the initial phase of the response may be present. The severe late hypoxic ventilatory depression in these rats could be a consequence of reduced NMDA activation of nitric oxide-cGMP signaling pathways involved in regulating prolonged excitatory inputs at the NTS (Haxhiu et al., 1995; Ogawa et al., 1995). Thus, we speculate that the primary respiratory pathology in MD rats may be attributable to altered glutamatergic receptor function in the caudal brainstem.

The central effects of hypoxia may activate inhibitory $\mathrm{GABA}_{\mathrm{A}}$ signaling pathways (Tabata et al., 2001) in the MD rat and contribute to the profound late hypoxic ventilatory depression. Although focal loss of $\mathrm{GABA}_{\mathrm{A}}$ receptors is apparent in specific areas of the caudal brainstem (Fig. 8), sufficient receptors may remain in other areas of the brainstem for preservation of GABAergic inhibitory influences. This is consistent with our Western blot analysis showing that the overall protein content of the major $\mathrm{GABA}_{\mathrm{A}}$ subunits is normal in the brainstem of the P21 MD rat. On the basis of our results, we speculate that, as these rats mature, they may develop a relative imbalance of stimulatory and inhibitory neurotransmission in response to hypoxia, which results in fatal hypoxic ventilatory depression.

CNS myelination in the rat proceeds in a caudal to rostral direction and is essentially complete by P21 in the brainstem. During late embryonic and early postnatal life in the rat, expression of the PLP gene also changes. The alternatively spliced isoform of the PLP gene DM20 is expressed during embryogenesis in nonmyelinating cells (Ikenaka et al., 1992; Timsit et al., 1992). PLP protein, in contrast, is thought to be expressed at a fairly late stage of oligodendrocyte differentiation, during myelination and myelin compaction (Nadon et al., 1990; Trapp et al., 1997). MD PLP/DM20 protein accumulates in the endoplasmic reticulum of the oligodendrocyte and is poorly transported to cell processes, resulting in reduced myelination and oligodendrocyte cell death (Gow et al., 1998). Thus, it is possible that the major defect in the MD pup, hypomyelination, alters development of myelinated, rapidly conducting neural pathways in the brainstem necessary for rapid response to sensory input such as hypoxia.

On the other hand, this study also demonstrates that the MD PLP gene is expressed in neurons in the medulla oblongata (Figs. $5,6)$. This finding is consistent with previous observations that the PLP gene is expressed in diverse cells, including neurons and cells in the thymus, spleen, lymph nodes, and heart (Campagnoni et al., 1992; Ikenaka et al., 1992). In this study, we also confirmed that the PLP promoter is expressed in the early postnatal period in neurons in the NTS, hypoglossal nucleus, ventrolateral medulla, and inferior olives (Fig. 6). The nonmyelin functions of the PLP gene in neurons are unknown. It is possible that mutated PLP/DM20 protein accumulates in neuronal cell bodies (Fig. 5), as it does in oligodendrocyte cell bodies, and that it has a comparable impact, potentially leading to cell death. This impact may be later and/or less in most of the neurons because of reduced amounts of the protein or reduced sensitivity of neurons to this misfolded protein. Because most of these brainstem nuclei have normal numbers of neurons, it is possible that defective PLP/ DM20 protein in neurons may affect their function before it actually leads to cell death, and the animal dies because of loss of function in these critical neurons. It is quite striking that the neurons in the respiratory neuraxis of the caudal brainstem have selective changes in gene expression, with reduced $\mathrm{GABA}_{\mathrm{A}}$ receptor, essentially no NMDA receptor, and normal ChAT. The finding that the number of NeuN-positive neurons is not significantly diminished in the NTS, DMV, and hypoglossal nucleus supports the concept that neurons in these areas are not (yet) dying but have significantly altered function.

PLP/DM20 has structural similarities to proteins with four transmembrane domains, some of which may function as ion channels. A possible role of PLP/DM20 as an ion pore is supported by the elevated $\mathrm{pH}$ in mouse jimpy oligodendrocytes and by a series of studies in lipid membranes (Ting-Beall et al., 1972; Diaz et al., 1990; Knapp et al., 1993). Transcription of a new member of the PLP gene family, whose function is unknown, has also been shown to be upregulated in the ventral medulla by hypercapnia (Shimokawa and Miura, 2000). It is conceivable that expression of mutant PLP in CNS neurons that control ventilatory response to hypoxia could alter maintenance of intracellular $\mathrm{pH}$, resulting in diverse pathologic changes in cellular function.

In this study, we focused on ventilatory chemosensory responses in the MD rat. It is likely that other functions of the caudal brainstem may be altered during postnatal development, including autonomic control of heart rate and blood pressure, as well as patency of the upper airway. Lack of protective autonomic reflex responses might also contribute to the pathologic response of the MD rat to hypoxia. 
In summary, the results of this study show that the MD PLP mutation causes pathologic alteration of respiratory control, accompanied by histopathology of the caudal brainstem, including dysmyelination, decrease in glutamatergic NMDA receptors, and to a lesser extent GABAergic receptors. These findings may be relevant to understanding of the "connatal" or infantile form of Pelizaeus Merzbacher disease. These children die in the first decade of life of causes that are incompletely understood. It is conceivable that expression of the mutant PLP gene in the connatal form of Pelizaeus Merzbacher could result in a severe disturbance of respiratory homeostasis, as in the MD pup, and contribute to early death of affected children

\section{References}

Ang RC, Hoop B, Kazemi H (1992) Role of glutamate as the central neurotransmitter in the hypoxic ventilatory response. J Appl Physiol 72:1480-1487.

Boison D, Stoffel W (1989) A point mutation in exon 3 (A-C, Thr 75-Pro) of the myelin proteolipid protein causes dysmyelination and oligodendrocyte death. EMBO J 8:3295-3302.

Boulloche J, Aicardi J (1986) Pelizaeus-Merzbacher disease: clinical and nosological study. J Child Neurol 1:233-239.

Campagnoni CW, Garbay B, Micevych P, Pribyl T, Kampf K, Handley VW, Campagnoni AT (1992) DM20 mRNA splice products of the myelin proteolipid protein gene are expressed in the murine heart. J Neurosci Res 33:148-155.

Ciriello J, Hrycyshyn AW, Calaresu FR (1981) Horseradish peroxidase study of brain stem projections of carotid sinus and aortic depressor nerves in the cat. J Auton Nerv Syst 4:43-61.

Cottle MK (1964) Degeneration studies of primary afferents of 1Xth and Xth cranial nerves in the cat. J Comp Neurol 122:329-343.

Cremers FP, Pfeiffer RA, van de Pol TJ, Hofker MH, Kruse TA, Wieringa B, Ropers HH (1987) An interstitial duplication of the X chromosome in a male allows physical fine mapping of probes from the Xq13-q22 region. Hum Genet 77:23-27.

Csiza CK, de Lahunta A (1979) Myelin deficiency, a neurologic mutant in the wistar rat. Am J Pathol 95:215-219.

Dentinger MP, Barron KD, Csiza CK (1982) Ultrastructure of the central nervous system in a myelin deficient rat. J Neurocytol 11:671-691.

Diaz RS, Monreal J, Lucas M (1990) Calcium movements mediated by proteolipid protein and nucleotides in liposomes prepared with the endogenous lipids from brain white matter. J Neurochem 55:1304-1309.

Ellis D, Malcom S (1994) Proteolipid protein gene dosage effect in Pelizaeus-Merzbacher Disease. Nat Genet 6:333-334.

Finley JCW, Katz D (1992) The central organization of carotid body afferent projections to the brainstem of the rat. Brain Res 572:108-116.

Funk GD, Johnson SM, Smith JC, Dong X, Lai J, Feldman JL (1997) Functional respiratory rhythm generating networks in neonatal mice lacking NMDAR1 gene. J Neurophysiol 78:1414-1420.

Garbern J, Cambi F, Shy M, Kamholtz J (1999) The molecular pathogenesis of Pelizaeus-Merzbacher disease. Arch Neurol 56:1210-1214.

Gow A, Southwood CM, Lazzarini RA (1998) Disrupted proteolipid protein trafficking results in oligodendrocyte apoptosis in an animal model of Pelizaeus-Merzbacher disease. J Cell Biol 140:925-934.

Gozal D, Gaultier C (2001) Evolving concepts of the maturation of central pathways underlying the hypoxic ventilatory response. Am J Resp Crit Care Med 164:325-329.

Gudz TI, Schneider TE, Haas TA, Macklin WB (2002) Myelin proteolipid protein forms a complex with integrins and may participate in integrin receptor signaling in oligodendrocytes. J Neurosci 22:7398-7407.

Haddad G, Donnelly DF, Bazzy-Asaad AR (1995) Developmental control of respiration, neurologic basis. In: Lung biology in health and disease, $\mathrm{Vol}$ 79, Regulation of breathing, Ed 2 (Dempsey JA, Pack AI, eds), pp 743-796. New York: Dekker.

Harding B, Ellis D, Malcom S (1995) A case of Peligaeus-Merzbacher disease showing increased dosage of the proteolipid protein gene. Neuropathol Appl Neurobiol 21:111-115.

Haxhiu MA, Chang CH, Dreshaj IA, Erokwu B, Prabhakar NR, Cherniak NS (1995) Nitric oxide and ventilatory response to hypoxia. Respir Physiol 101:257-266.

Ikenaka K, Kagawa T, Mikoshiba K (1992) Selective expression of DM-20, an alternatively spliced myelin proteolipid protein gene product, in developing nervous system and in nonglial cells. J Neurochem 58:2248-2253.

Inoue K, Osaka H, Imaizumi K, Nezu A, Takanashi J, Arii J, Murayama K, Ono J, Kikawa Y, Mito T, Shaffer LG, Lupski J (1999) Proteolipid protein gene duplications causing Pelizaeus-Merzbacher disease: molecular mechanism and phenotypic manifestations. Ann Neurol 45:624-632.

Jacobson S (1963) Sequence of myelinization in the brain of the albino rat. A. Cerebral cortex, thalamus and related structures. J Comp Neurol 121:5-29.

Jordan D (1994) Central integration of chemoreceptor afferent activity in arterial chemoreceptors. In: Cell to system (O'Regan RE, ed), pp 87-91. New York: Plenum.

Knapp PE (1996) Proteolipid protein: is it more than just a structural component of myelin? Dev Neurosci 18:297-308.

Knapp PE, Booth CS, Skoff RP (1993) The pH of jimpy glia is increased: intracellular measurements using fluorescent laser cytometry. J Dev Neurosci 11:215-226.

Kumar S, Macklin WB, Gordon MN, Espinosa de los Monteros A, Cole R, Scully SA, deVellis J (1990) Transcriptional regulation studies of myelin-associated genes in myelin-deficient mutant rats. Dev Neurosci 12:316-323.

Lin J, Sugihara C, Huang J, Here D, De Via C, Bancalari E (1996) Effect of $\mathrm{N}$-methyl-D-aspartate receptor blockade on hypoxic ventilatory response in unanesthetized piglets. J Appl Physiol 80:1759-1763.

Loeschcke HH (1982) Central chemosensitivity and the reaction theory. J Physiol (Lond) 332:1-24.

Loewy AD, Burton H (1978) Nuclei of the solitary tract: efferent projections to the lower brainstem and spinal cord of the cat. J Comp Neurol 181:421-450.

Mallon BS, Shick HE, Kidd GJ, Macklin WB (2002) Proteolipid promotor activity distinguishes two populations of NG2-positive cells throughout neonatal cortical development. J Neurosci 22:876-885.

Melton JE, Neubauer JA, Edelman NH (1990) GABA antagonism reverses hypoxic respiratory depression in the cat. J Appl Physiol 69:1296-1301.

Miller MJ, Haxhiu MA, Haxhiu-Poskurica B, Dreshaj IA, DiFiore JM, Martin RJ (2000) Recurrent hypoxic exposure and reflex responses during development in the piglet. Respir Physiol 123:51-61.

Miller MJ, Haxhiu MA, Martin R (2003) Chemical control of breathing from the fetus through the newborn period. In: Respiratory control and disorders in the newborn, Vol 173 (Matthew O, ed), pp 83-103. New York: Dekker.

Miyawaki T, Goodchild AK, Pilowski PM (2002) Evidence for a tonic GABA-ergic inhibition of excitatory respiratory-related afferents to presympathetic neurons in the rostral ventrolateral medulla. Brain Res 941:56-62.

Mullen RJ, Buck CR, Smith A (1992) NeuN, a neuronal specific nuclear protein in vertebrates. Development 116:201-211.

Nadon NL, Ducan ID, Hudson LD (1990) A point mutation in the proteolipid protein gene of the "shaking pup" interrupts oligodendrocyte development. Development 110:529-537.

Nakanishi S (1992) Molecular diversity of glutamate receptors and implications for brain function. Science 258:597-603.

Nave K-A (1994) Neurological mouse mutants and the genes of myelin. J Neurosci Res 38:607-612.

Ogawa H, Mizusawa A, Kikuchi Y, Hida W, Miki H, Shirato K (1995) Nitric oxide as a retrograde messenger in the nucleus tractus solitarius of rats during hypoxia. J Physiol (Lond) 486:495-504.

Ohtake PJ, Torres JE, Gozal YM, Graff GR, Gozal D (1998) NMDA receptors mediate peripheral chemoreceptor afferent input in the conscious rat. J Appl Physiol 84:853-861.

Ohtake PJ, Simakajornboon N, Fehniger MD, Xue Y, Gozal D (2000) $\mathrm{N}$-methyl-D-aspartate receptor expression in the nucleus tractus solitarii and maturation of hypoxic ventilatory response in the rat. Am J Resp Crit Care Med 162:1140-1147.

Panneton WM, Loewy AD (1980) Projections of carotid sinus nerve to the nucleus of the solitary tract in the cat. Brain Res 191:239-244.

Paxinos G, Watson C (1986) The rat brain in stereotaxic coordinates. San Diego: Academic.

Raskind WH, Williams CA, Hudson ID, Bird TD (1991) Complete deletion of the proteolipid protein gene (PLP) in a family with X-linked PelizaeusMerzbacher disease. Am J Hum Genet 49:1355-1360.

Seitelberger F, Urbanits S, Nave KA (2002) Pelizaeus-Merzbacher Disease. 
In: Neurodystrophies and neurolipidoses (Moser WH, ed), pp 559-579. Amsterdam: Elsevier.

Shimokawa N, Miura M (2000) Rhombex-29, a novel gene of the PLP/ DM20 family cloned from rat medulla oblongata by differential display. J Neurosci Res 62:1-8.

Smith JC, Morrison DE, Ellenberger HH, Otto MR, Feldman JL (1989) Brainstem projections to the major respiratory neuron populations in the medulla of the cat. J Comp Neurol 281:69-96.

Tabata M, Kurosawa H, Kikuchi Y, Hida W, Ogawa H, Okabe S, Tun Y, Hattori T, Shirato K (2001) Role of GABA within the nucleus tractus solitarii in the hypoxic ventilatory decline of awake rats. Am J Physiol Regul Integr Comp Physiol 281:R1411-R1419.

Timsit SG, Bally-Cuif L, Colman DR, Zalc B (1992) DM-20 mRNA is expressed during the embryonic development of the nervous system of the mouse. J Neurochem 58:1172-1175.

Ting-Beall HP, Lees MB, Robertson JD (1972) Interactions of Foch-Lees proteolipid apoprotein with planar lipid bilayers. J Membrane Biol 51:33-46.

Trapp BD, Nishiyama A, Cheng DP, Macklin WB (1997) Differentiation and death of premyelinating oligodendrocytes in developing rodent brain. J Cell Biol 137:459-468.

Watson RE, Weigand SJ, Clough RW, Hoffman GE (1985) Use of cryoprotectant to maintain long term peptide immunoreactivity and tissue morphology. Peptides 7:155-159.

Yamamoto T, Nanba E, Zhang H, Sasaki M, Komaki H, Takeshita K (1998) Jimpy(msd) mouse mutation and connatal Pelizaeus-Merzbacher disease. Am J Med Genet 75:439-440.

Yool DA, Edgar JM, Montague P, Malcom S (2000) The proteolipid protein gene and myelin disorders in man and animal models. Hum Mol Genet 9:987-992.

Zuperku EJ, McCrimmon DR (2002) Gain modulation of respiratory neurons. Respir Physiol Neurobiol 131:121-133. 